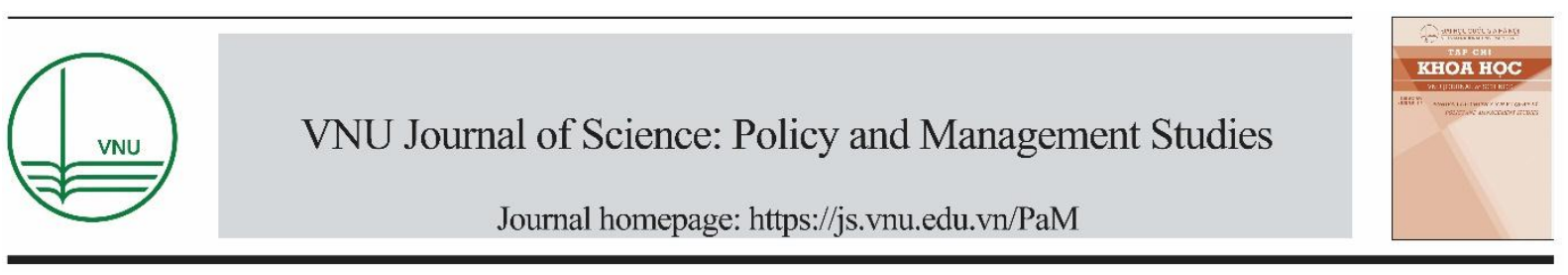

Original Article

\title{
Middle Income Trap and Challenges Facing Developing Countries
}

\author{
Nguyen Quynh Huy* \\ University of Economics Ho Chi Minh City, 59C Nguyen Dinh Chieu, District 3, Ho Chi Minh City, Vietnam
}

Received 29 July 2019

Revised 16 September 2019; Accepted 18 September 2019

\begin{abstract}
The middle-income trap is becoming a topic that attracts many governments' interest. The development experience has shown that only a few countries have succeeded in escaping the middle-income trap since the 1960s. The paper focuses on the differences in the development context between the current middle-income countries and the groups of countries that have successfully industrialized. The research results show that the countries that had escaped the middleincome trap had higher human resource quality, especially evident in the proportion of people involved in research and development activities. They also had lower inequality and informal sector. In particular, these countries had a deeper linkage with the foreign invested sector in upgrading technology during the development process. Therefore, the paper points out the important prepositions that the current middle-income countries need to implement if they want to overcome the middle-income trap.
\end{abstract}

Keywords: Middle-income trap, inequality, industrialization, foreign investment.

\footnotetext{
${ }^{*}$ Corresponding author.

E-mail address: huynquynh@ueh.edu.vn
}

https://doi.org/10.25073/2588-1116/vnupam.4175 


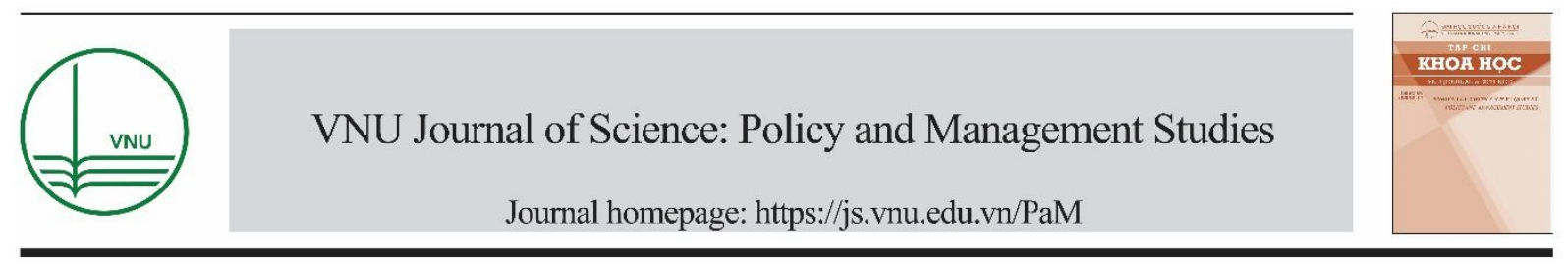

\title{
Bẫy thu nhập trung bình và thách thức cho các nước đang phát triển
}

\author{
Nguyễn Quỳnh Huy* \\ Đại học Kinh tế TP Hồ Chí Minh, 59C Nguyễn Đình Chiểu, Phuờng 6, Quận 3, Hồ Chí Minh, Việt Nam \\ Nhận ngày 29 tháng 7 năm 2019 \\ Chỉnh sửa ngày 16 tháng 9 năm 2019; Chấp nhận đăng ngày 18 tháng 9 năm 2019
}

\begin{abstract}
Tóm tắt: Bẫy thu nhập trung bình đang trở thành chủ đề thu hút sự quan tâm của chính phủ nhiều nước. Thực tiễn về quá trình phát triển đã chỉ ra rằng, kể từ năm 1960 trở lại đây, chỉ có vài nước thành công khi thoát khỏi bẫy thu nhập trung bình. Bài viết tập trung đi sâu vào sự khác biệt về bối cảnh phát triển giữa các nước thu nhập trung bình hiện nay và nhóm nước đã thành công trong quá trình công nghiệp hoá. Kết quả nghiên cứu cho thấy, các nước thành công trong thoát khỏi bẫy thu nhập trung bình có chất lượng nhân lực cao hơn, nhất là tỷ lệ nhân lực tham gia hoạt động nghiên cứu và phát triển, mức độ bất bình đẳng và khu vực phi chính thức thấp hơn. Đặc biệt các nước này có mức độ liên kết sâu với khu vực có vốn đầu tư nước ngoài và thúc đẩy cơ chế nâng cấp công nghệ trong quá trình phát triển. Chính vì vậy, bài viết đã chỉ ra các tiền đề quan trọng để các nước thu nhập trung bình hiện nay cần ưu tiên thực hiện nếu muốn thoát khỏi bẫy thu nhập trung bình.
\end{abstract}

Tù khoá: Bẫy thu nhập trung bình, bất bình đẳng, công nghiệp hoá, đầu tư nước ngoài.

\section{Giới thiệu}

Thuật ngữ "bẫy thu nhập trung bình" đã trở thành chủ đề quan tâm của nhiều quốc gia, đặc biệt ở khu vực Châu Á, nơi đang ưu tiên tập trung các chính sách để thúc đẩy tăng trưởng kinh tế khi đã được trình độ mở mức thu nhập trung bình. Tuy nhiên, xét ở phạm vi toàn cầu thì từ năm 1960 trở lại đây, chỉ có 13 nước trong tổng số 101 nước thu nhập trung bình đã thành công trong việc chuyển đồi từ nước thu nhập trung

\footnotetext{
*Tác giả liên hệ.

Địa chỉemail: huynquynh@ueh.edu.vn
}

https://doi.org/10.25073/2588-1116/vnupam.4175 bình sang nước thu nhập cao trong những năm 1980s và 1990 s $^{1}$. Khu vực Đông Ấ với các mô hình thành công như Hàn Quốc, Đài Loan, và Singapore. Một số nước ở khu vực Đông Nam Á đã rất thành công trong thúc đẩy tăng trưởng, và giảm nghèo nhưng vẫn chưa thể quá độ để đạt được nước có mức thu nhập cao như 13 nước đã thành công đạt được. Thái Lan và Malaysia vẫn kẹt ở mức thu nhập trung bình cho dù có xuất phát điểm như nhiều nước đã đạt ở mức thu nhập cao. Indonesia, Phillippines và Việt Nam thậm

\footnotetext{
${ }^{1}$ Ngân hàng thế giới [1]
} 
chí còn ở phía sau dù đã đạt tăng trưởng cao nhưng còn khoảng cách khá xa với so với nhóm nước như Malaysia hay Thái Lan.

Vào năm 1952, Nhật Bản là nước có thu nhập trung bình thấp, nhưng chỉ 15 năm sau tiến lên nước thu nhập trung bình cao và thêm 13 năm nữa trở thành cường quốc kinh tế. Tương tự như vậy, nền kinh tế Hàn Quốc chỉ mất 16 năm (từ năm 1971 đến 1987) để chuyển từ nước thu nhập trung bình thấp lên trung bình cao và chỉ mất thêm 10 năm nữa để tiến lên hàng các nước phát triển. Đài Loan trở thành nền kinh tế tiên tiến vào năm 1995, chỉ tốn 12 năm kể từ giai đoạn thu nhập trung bình cao [2]. Câu chuyện Trung Quốc với bước tiến tương tự đang diễn ra, bất chấp sự khác biệt về chính trị. Tuy nhiên, Philippines từ giữa những năm 1950 thu nhập đầu người cao hơn cả Hàn Quốc, nhưng 40 năm sau vẫn ở mức thu nhập trung bình thấp.

Một câu hỏi lớn đặt ra là: điều gì đã dẫn đến sự khác biệt về kết quả tăng trưởng và quá độ chuyển sang thu nhập cao của 13 nước trong tổng số 101 nước đạt mức thu nhập trung bình từ năm 1960? Mở cửa thương mại quốc tế, thu hút đầu tư nước ngoài được xem là những điều kiện cần thiết để các nước ở mức thu nhập trung bình thúc đẩy tăng trưởng. Ohno [3] cũng nhấn mạnh đến vai trò của chính sách công nghiệp, chiến lược huy động và sử dụng vốn đầu tư trực tiếp nước ngoài $(\mathrm{FDI})$, và vai trò của nghiên cứu và phát triển trong quá trình nâng cấp nấc thang công nghệ. Tuy nhiên, những điều kiện này dường như là chưa đủ để các nhiều nước đạt được mức thu nhập cao. Chính sự khác biệt về bối cảnh ban đầu, thể chế thúc đẩy cơ hội đổi mới sáng tạo để rút ngắn khoảng cách với các nước tiên phong về công nghệ, thể chế thúc đẩy phân bổ và sử dụng vốn hiệu quả, và thể chế cho phép tương tác phức tạp trong nền kinh tế chính là cơ sở điều kiện đủ để bắt kịp các nước công nghệ tiên tiến. Hầu hết các nước đã dựa vào $\mathrm{FDI}$, vào các ngành thâm dụng lao động trong giai đoạn đầu khi chuyển từ thu nhập thấp sang thu nhập trung bình. Tuy nhiên, chính những yếu tố này lại tạo sự phân chia lớn và trở thành nhân tố cản trở việc nâng cấp các chính sách và xây dựng thể chế phù hợp để phát triển và đạt mức thu nhập cao. Sự tách rời giữa khu vực trong nước và khu vực nước ngoài, giữa khu vực chính thức và phi chính thức mới khiến cho năng lực quản lý sự phức tạp của nền kinh tế kém và khó định hướng. Hiện nay chưa có nghiên cứu nào tổng kết đặc trưng của các nước thu nhập trung bình so với đặc trưng của các nước thu nhập trung bình trước kia nhưng đã thành các nước phát triển. Đây cũng chính là mục tiêu của bài viết nhằm phân tích những điểm khác biệt giữa nhóm nước đã thành công và chưa thành công khi từ thu nhập trung bình lên trạng thái thu nhâp cao.

\section{Bẫy thu nhập trung bình và cách giải thích phổ biến}

Thuật ngữ "bẫy thu nhập trung bình", được giới thiệu trong báo cáo "Đông Â phục hưng" của Ngân hàng Thế giới [4], ban đầu đã nhẩn mạnh vào khả năng cạnh tranh của một quốc gia. Báo cáo đã chỉ ra vai trò của hội nhập kinh tế và cải cách thể chế là những thành phần quan trọng cho phép các nước Đông Á phát triển nhanh và chuyển sang các nước có thu nhập cao. Kết quả nghiên cứu đã giới thiệu những kinh nghiệm thành công của các quốc gia Đông Á, sau cuộc khủng hoảng tài chính châu Á năm 1997-98 và trở thành khu vực năng động nhất trong một thế giới toàn cầu hóa. Báo cáo cũng lần đầu tiên xác định các quốc gia đang trải qua sự suy giảm tăng trưởng và bị kẹt giữa các đối thủ cạnh tranh có thu nhập thấp và cho thấy không có khả năng để thách thức đổi mới để đạt mức thu nhập cao trong các ngành công nghiệp đang thay đổi nhanh chóng trên chuỗi sản xuất toàn cầu.

Nghiên cứu của Spence [5] đã chỉ ra rằng, các quốc gia gặp nhiều thách thức trong việc đạt mức thu nhập cao khi đã ở mức thu nhập trung bình, điều này gắn liền với thuật ngữ bẫy thu nhập trung bình. Hình 1 chỉ ra các giai đoạn phát triển của một nền kinh tế, khi đã đạt đến điểm $\mathrm{C}$ (giai đoạn thu nhập trung bình), nhiều thách thức mới đặt $\mathrm{ra}$ để có thể chuyển từ $\mathrm{C}$ đến $\mathrm{D}$. Giai đoạn từ $\mathrm{B}-\mathrm{C}$ như hình 1 đã chỉ ra được đặc trưng bởi định hướng đầu vào (thâm dụng lao động và vốn). Đầu tư cho hạ tầng và sản xuất công nghiệp 
được mở rộng. Tuy nhiên, để duy trì từ $\mathrm{C}$ đến $\mathrm{D}$ gắn với tăng trưởng bền vững, quốc gia cần phải định hướng phát triển và làm chủ công nghệ và nguồn lực được sử dụng hiệu quả. Năng suất nhân tố tổng hợp (TFP) đóng góp chính vào quá trình tăng trưởng của nền kinh tế. Hai điều kiện tiền đề cho dịch chuyển từ $\mathrm{C}$ đến $\mathrm{D}$ đó chính là đầu tư công vào cơ sở hạ tầng, vốn con người để phát triển các ngành công nghiệp thâm dụng công nghệ mới và tri thức, đồng thời duy trì thể chế chất lượng cao trong việc tạo ra khu vực tư nhân năng động, sáng tạo. Rodrik [6] đã nhấn mạnh đến thể chế chất lượng cao khi thúc đẩy bộ máy chính phủ có chất lượng, chính phủ hiệu quả, hiệu lực và một khu vực tư nhân mạnh, qua đó mới sử dụng nguồn lực một cách có hiệu quả.

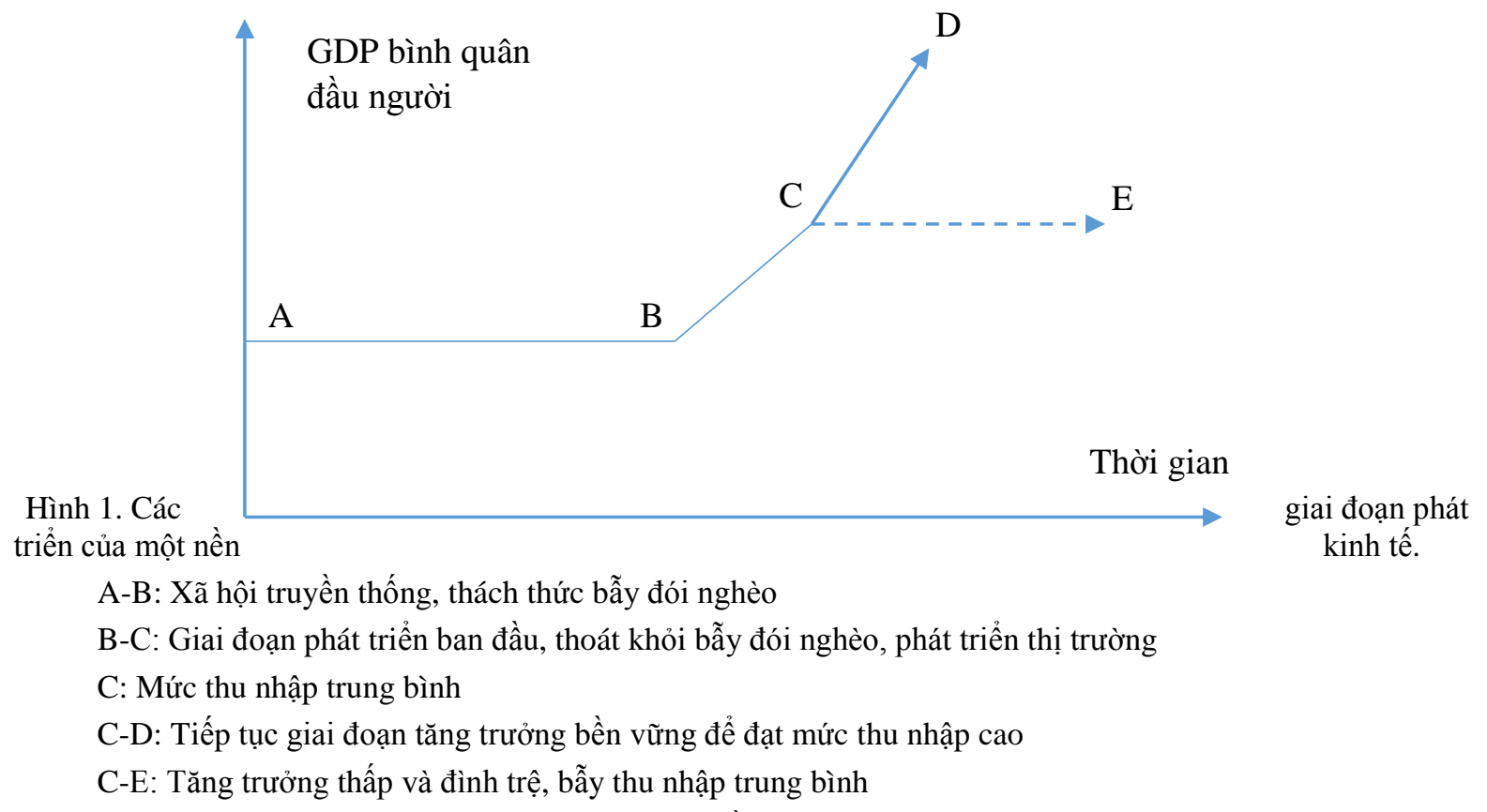

Nguồn: Spence [5]

Bẫy thu nhập trung bình xảy ra khi một nước bị mắc kẹt tại mức thu nhập mà việc đạt mức thu nhập này được quyết định bởi nguồn lực và lợi thế ban đầu, và không thể vượt quá mức giới hạn đó [3]. Một quốc gia đang ở trong bẫy thu nhập trung bình nếu quốc gia đó cho thấy không có khả năng để thách thức sáng tạo có thu nhập cao trong một ngành công nghiệp thay đổi nhanh chóng. Vượt qua được bẫy thu nhập trung bình là kết quả của một chiến lược phát triển đúng đắn và chính sách phù hợp. Cũng có quan điểm cho rằng bẫy thu nhập trung bình chỉ là kết quả của một chiến lược tăng trưởng không thích hợp. Các quốc gia có thu nhập trung bình cần phải thay đổi chiến lược tăng trưởng để chuyển đổi thuận lợi hơn sang tình trạng có thu nhập cao. Những phát hiện của nghiên cứu cho thấy các quốc gia có thu nhập trung bình cần các chiến lược để duy trì tốc độ tăng trưởng cao trong một thời gian dài, và các chiến lược này khác với các chiến lược chuyển từ tình trạng thu nhập thấp sang thu nhập trung bình. Một quốc gia có thu nhập trung bình với một chiến lược tăng trưởng không thích hợp sẽ phải đối mặt với khó khăn để chuyển sang cấp độ tiếp theo, và do đó có thể bị mắc kẹt ở giai đoạn thu nhập trung bình. 
Ohno [3] cho rằng bẫy thu nhập trung bình nói chung là một hiện tượng "không phải châu Á" vì sự tăng trưởng nhanh của các nền kinh tế châu Á so với các nước Mỹ La tinh đang đối mặt với bẫy thu nhập trung bình. Tuy nhiên, Ohno [3] cũng cho rằng các nước như Việt Nam có nguy cơ rơi vào bẫy thu nhập trung bình trong tương lai gần vì mức tăng trưởng GDP bình quân đầu người hiện tại của họ thấp hơn nhiều so với mức tăng trưởng bình quân GDP bình quân đầu người cần thiết để chuyển sang mức cao.
Tiền công
Bắt đầu thu
hút FDI
Nội lực công
nghiệp hỗ trợ
Nội lực hoá kỹ
năng công
nghệ
Nội lực hoá
nghiệp hoá
đổi mới

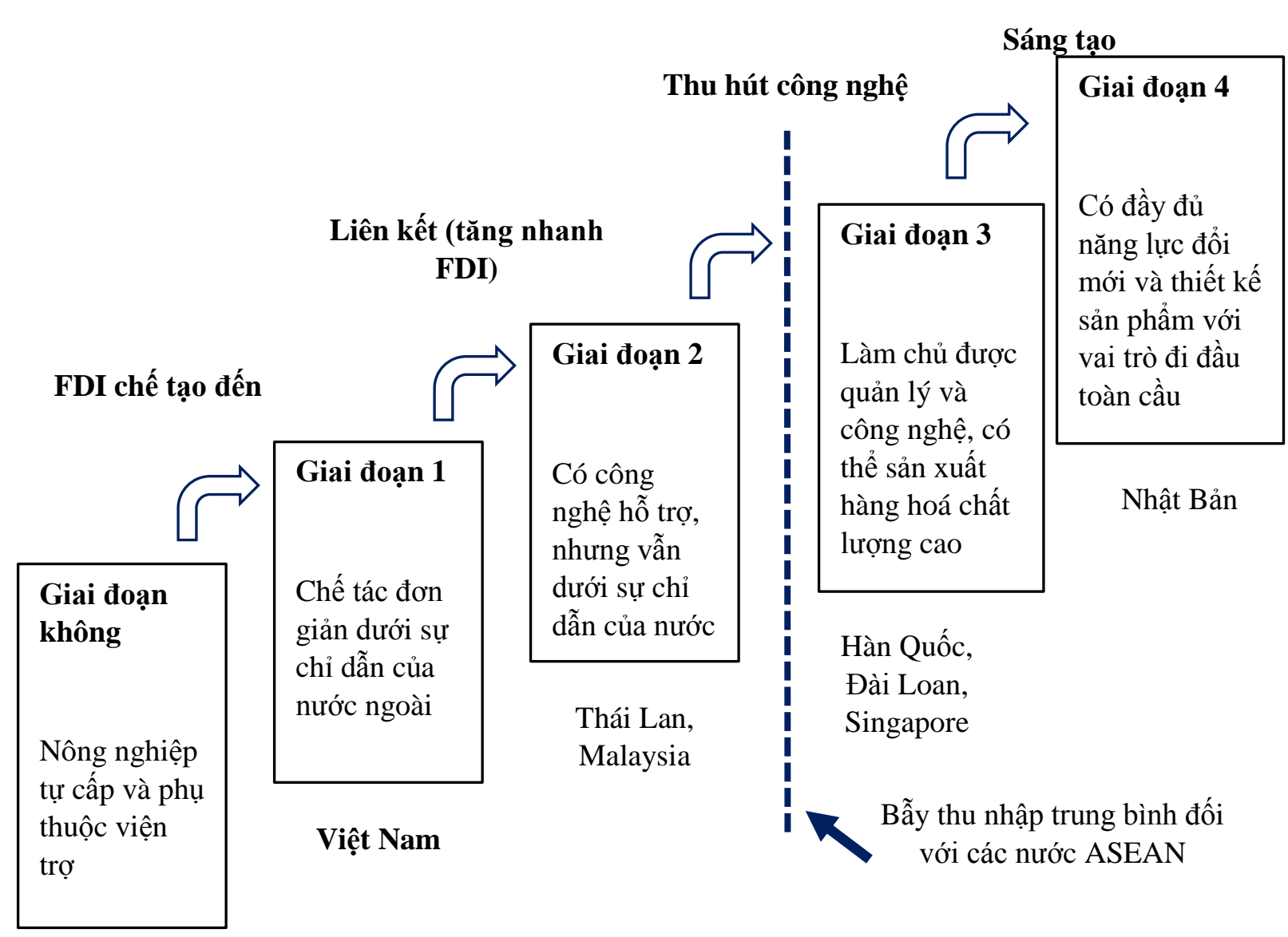

Hình 2. Các giai đoạn công nghiệp hoá từ mô hình phát triển của các nước ở Đông Á

Nguồn: Kenichi Ohno, Learning to industrialize: from given growth to policy-aided value creation, Routledge, London [3]. 
Hình 2 cung cấp thông tin về vai trò của chính phủ các nước Đông Á đã thành công trong quá trình công nghiệp hoá. Từ viễn cảnh của Nhật Bản, sau đó là các nước như Hàn Quốc, Singapore và Đài Loan, sự cất cánh của một nền kinh tế thường bắt đầu từ sự hiện diện ồ ạt của các công ty chế tạo có vốn đầu tư nước ngoài thực hiện các hoạt động lắp ráp đơn giản hoặc chế biến các sản phẩm công nghiệp nhẹ phục vụ xuất khẩu, như dệt may, giày dép và thực phẩm. Các thiết bị và linh kiện điện tử cũng có thể được sản xuất theo cách này. Trong giai đoạn đầu (giai đoạn 1), tất cả các hoạt động như thiết kế, công nghệ, sản xuất và marketing đều do người nước ngoài hướng dẫn, nguyên vật liệu chính và phụ tùng được nhập khẩu, còn quốc gia tiếp nhận đầu tư chỉ đóng góp nguồn lao động giản đơn và đất công nghiệp. Mặc dù quá trình này tạo ra công ăn việc làm và thu nhập cho người nghèo, song giá trị nội tại rất nhỏ và giá trị do người nước ngoài tạo ra chiếm ưu thế. Công nghiệp hoá của Việt Nam hiện nay về cơ bản đang ở giai đoạn này.

Như vậy, một quốc gia có thu nhập thấp đã trải qua chiến tranh, bất ổn chính trị, kế hoạch hóa xã hội chủ nghĩa hay những yếu kém nghiêm trọng trong quản lý kinh tế thường có đặc trưng là cơ cấu kinh tế dễ đổ vỡ. Nền kinh tế như vậy chủ yếu dựa vào khai thác các nguồn lực, xuất khẩu nông sản độc canh, nông nghiệp tự cung tự cấp hoặc viện trợ của nước ngoài. Giá trị nội tại do các ngành công nghiệp truyền thống như khai khoáng và nông nghiệp tạo ra thường rất thấp, nhưng do không có các hoạt động chế tạo khiến cho giá trị này chiếm tỷ trọng khá cao trong giá trị sản xuất và thương mại. Đây chính là giai đoạn bắt đầu từ con số không của một quá trình dài tiến tới công nghiệp hoá.

Trong giai đoạn hai, khi số vốn FDI đã được tích luỹ và quy mô sản xuất mở rộng, nguồn cung nội địa về phụ tùng và linh kiện bắt đầu tăng lên. Điều này diễn ra một phần là do các nhà cung cấp FDI đầu tư vào và một phần là do sự ra đời của các nhà cung cấp trong nước. Khi điều này xảy ra, các công ty lắp ráp trở nên cạnh tranh hơn và mối liên kết giữa công ty lắp ráp và nhà cung cấp bắt đầu xuất hiện. Ngành công nghiệp này tăng trưởng mạnh về lượng do khả năng cung cấp các yếu tố đầu vào trong nước gia tăng. Giá trị nội tại tăng không nhiều nhưng sản xuất về cơ bản vẫn chịu sự quản lý và chỉ đạo của người nước ngoài. Hiển nhiên là tiền lương và thu nhập trong nước không thể tăng lên quá nhiều nếu tất cả các công đoạn quan trọng vẫn do người nước ngoài thực hiện. Thái Lan và Malaixia đã đạt đến giai đoạn này. Các nước có xu hướng "tốt nghiệp" viện trợ ODA.

Giai đoạn tiếp theo là giai đoạn nội lực hoá kỹ năng và tri thức thông qua tích luỹ vốn con người trong ngành công nghiệp. Lao động trong nước phải thay thế cho lao động nước ngoài trong tất cả các lĩnh vực sản xuất bao gồm cả quản lý, công nghệ, thiết kế, vận hành nhà máy, hậu cần, quản lý chất lượng và marketing. Vì sự phụ thuộc vào người nước ngoài đã giảm nên giá trị nội tại tăng lên rõ rệt. Quốc gia trở thành một nước xuất khẩu các sản phẩm chế tạo chất lượng cao, thách thức những đồi thủ cạnh tranh đi trước và xác lập lại vị trí của mình trên bức tranh công nghiệp toàn cầu. Hàn Quốc và Đài Loan là những nhà sản xuất như vậy.

Trong giai đoạn cuối cùng, quốc gia có năng lực tạo ra sản phẩm mới và dẫn đầu xu thế thị trường toàn cầu. Nhật, $\mathrm{My}$, và một số nước thành viên Liên minh Châu Âu chính là những nhà phát minh công nghiệp kiểu này. Tuy nhiên, không phải tất cả các quốc gia đều đạt được những bước tiến trong quá trình công nghiệp hoá. Nhiều quốc gia có quá ít FDI đầu tư vào sản xuất nên vẫn dậm chân tại chỗ ở giai đoạn số không. Thậm chí sau khi đạt được giai đoạn đầu tiên, việc tiếp tục bước lên những nấc thang mới trở nên ngày càng khó khăn. Một nhóm các nước khác thì bị mắc kẹt ở giai đoạn hai vì họ thất bại trong việc nâng cao chất lượng vốn con người và cơ cấu công nghiệp. Hiện tượng này thường được gọi là bẫy thu nhập trung bình [3].

\section{Thách thức thể chế cho các nước thu nhập trung bình hiện nay trong quá trình chuyển đổi}

Các nước thu nhập trung bình hiện nay đang phải đối mặt với thách thức lớn hơn so với các 
thách thức mà các nước như Hàn Quốc, Đài Loan hay Singapore đã từng trải qua. Những thách thức như tiếp cận công nghệ, bằng sáng chế của các nước tiên tiến, ưu tiên nguồn lực cho phát triển thay vì phân tán nguồn lực như trường hợp của Hàn Quốc dưới sự bảo trợ an ninh của Mỹ, môi trường thương mại và đầu tư quốc tế thuận lợi khi xu hướng mở cửa và toàn cầu hoá là phổ biến. Trung Quốc là trường hợp đặc biệt khi thành công trong việc nâng cao nấc thang công nghệ khi cải cách thể chế để yêu cầu các công ty nước ngoài chuyển giao công nghệ và tranh thủ được các nguồn công nghệ tiên tiến hay mua bằng sáng chế. Tuy nhiên, khi các nước có trình độ khoa học công nghệ tìm cách thay đổi và gây sức ép, vô hình chung đã đẩy nhiều nước thu nhập trung bình hiện nay không thể thực hiện bước đi như Trung Quốc đã làm suốt từ năm 1979 đến nay và tạo ra khoảng cách lớn về khả năng tiếp cận khoa học công nghệ. Câu chuyện về sự thành công của Huwei và ZTE cũng như các ngành công nghiệp chế tạo và công nghệ của Trung Quốc là minh chứng cho thấy khả năng tận dụng cơ hội để thay đổi. Tuy nhiên, đối với các nước thu nhập trung bình hiện nay, xuất phát điểm và bối cảnh rất khác so với các nước đã chuyển đổi thành công, cụ thể một số lĩnh vực như sau:

\section{* Giáo dục}

Hầu hết các lý thuyết đã nhấn mạnh đến tầm quan trọng của giáo dục đến thoát khỏi bẫy thu nhập trung bình. Tuy nhiên, cho dù có đầu tư mạnh cho giáo dục thì thành quả của các nước thu nhập trung bình hiện nay vẫn còn khá xa so với các nước thành công như ở khu vực Đông Á đã đạt được trong giai đoạn $\mathrm{C}$ như ở hình 1 đã chỉ ra. Bảng 1 chỉ ra sự khác biệt về vốn con người của giữa các nhóm nước khi cùng ở mức thu nhập trung bình. Kết quả bảng 1 cho thấy, ở cùng mức thu nhập trung bình thì nhóm nước hiện nay có khoảng cách khá xa so với giai đoạn thu nhập trung bình của các nước Đông Á (Hàn Quốc, Đài Loan, Singapore).

Bảng 1. So sánh vốn con người giữa các nhóm nước có cùng mức thu nhập trung bình

\begin{tabular}{lll}
\hline & $\begin{array}{l}\text { Các nước thu nhập trung bình hiện } \\
\text { nay (2009-2016) }\end{array}$ & $\begin{array}{l}\text { Các nước Đông Á ở giai đoạn } \\
\text { thu nhập trung bình }\end{array}$ \\
\hline $\begin{array}{l}\text { Tỷ lệ lực lượng lao động có trình } \\
\text { độ đại học }(\%)\end{array}$ & 19 & 34 \\
$\begin{array}{l}\text { Đội ngũ tham gia nghiên cứu và } \\
\text { phát triển (R \& D) }(\%)\end{array}$ & 3 & 11 \\
\hline
\end{tabular}

Ghi chú: Các nước thu nhập trung bình là các nước có mức thu nhập từ 1026 USD đến 12475 USD tính theo giá trị năm 2011, dựa trên cách tiếp cận của Ngân hàng thế giới (http://www.worldbank.org/en/country/mic)

Nguồn: Được tính toán từ cơ sở dữ liệu của Ngân hàng thế giới cho các nhóm nước thu nhập trung bình, http://www.worldbank.org/en/country/mic (10/04/2019) [7]

* Nghiên cúu và phát triển $(R \& D)$

Tương tự như khác biệt về trình độ nhân lực giữa 2 nhóm nước, khác biệt trong đầu tư vào hoạt động nghiên cứu và phát triển giữa 2 nhóm này cũng rất chênh lệch nhau. Các nước thu nhập trung bình hiện nay chịu tác động của chiến lược phát triển các ngành công nghiệp thâm dụng lao động trước đó, đồng thời các công ty đa quốc gia chi phối ngành công nghiệp chế tạo, điều này đã thúc đẩy tăng trưởng, nhất là xuất khẩu, nhưng không thúc đẩy đầu tư mạnh vào $\mathrm{R} \& \mathrm{D}$. Câu chuyện đầu tư của Samsung vào Việt Nam và sự khác biệt giữa khu vực FDI và trong nước là minh chứng rõ nét cho quá trình tăng trưởng của Việt Nam. Đầu tư cho R\&D đang là chìa khoá và thách thức phía trước cho các nước thu nhập trung bình hiện nay. Bảng 2 cung cấp thông tin về tỷ lệ đầu tư vào $R \& D$ của 2 nhóm nước có cùng mức thu nhập trung bình. Sự khác biệt lớn về đầu tư cho R\&D (theo tỷ lệ phần trăm của GDP) đã chỉ ra thách thức rất lớn của các nước 
thu nhập trung bình hiện nay trong việc xây dựng thể chế sau này. Quá trình đào tạo và tuyển dụng đội ngũ $R \& D$ yêu cầu sự hợp tác giữa các doanh nghiệp tư nhân, viện nghiên cứu, các trường đại học và đổi mới các chương trình và đòi hỏi phải có thể chế để phối hợp và thúc đẩy $R \& D$.

Bảng 2. Tỷ lệ đầu tư trong R\&D (\% của GDP)

Các nước thu Các nước nhập trung Đông Á ở giai bình hiện nay đoạn thu nhập (2009-2016) trung bình

\begin{tabular}{lll}
\hline R\&D & 0.7 & 3.1 \\
\hline
\end{tabular}

Nguồn: Được tính toán từ cơ sở dữ liệu của Ngân hàng thế giới cho các nhóm nước thu nhập trung bình, http://www.worldbank.org/en/country/mic $(12 / 04 / 2019)$ [7]

\section{* Bất bình đẳng:}

Các nước thu nhập trung bình hiện nay có mức bất bình đẳng cao hơn so với các nước đã thành công công nghiệp hoá. Bất bình đẳng lớn sẽ khiến chính trị khó có sự đồng thuận và dễ bị tổn thương do không đạt được sự tham gia và hỗ trợ của người dân, và liên minh thúc đẩy cải cách [8]. Bên cạnh đó, bất bỉnh đẳng lớn sẽ làm giảm năng lực của bộ máy, phát triển các nhóm lợi ích và phân tán nguồn lực vào chi tiêu kém hiệu quả [9]. Bất bình đẳng lớn cũng thúc đẩy chủ nghĩa dân tuý thông qua các hoạt động tái phân phối lại thiếu bền vững như kiểm soát giá và trợ cấp. Những bóp méo như ở Thái Lan và Venezuela với chính sách thu mua lúa gạo và trợ cấp cho người nghèo đã dẫn đến thúc đẩy ưu tiên và giảm cơ hội để nâng cấp hệ thống công nghiệp khi chủ nghĩa dân tuý được đề cao. Kết quả từ bảng 3 cho thấy, các nước thu nhập trung bình hiện nay đang phải đối mặt với tỷ lệ bất bình đẳng lớn hơn so với các nước đã thành công thoát khỏi bẫy thu nhập trung bình khi ở cùng giai đoạn, điều này đang đặt ra nhiều thách thức trong hệ thống quản trị quốc gia.
Bảng 3. Bất bình đẳng giữa hai nhóm nước

\begin{tabular}{lll}
\hline & $\begin{array}{l}\text { Các nước thu } \\
\text { nhập trung } \\
\text { bình hiện nay } \\
(2005-2016)\end{array}$ & $\begin{array}{l}\text { Các nước } \\
\text { Đông Á ở giai } \\
\text { đoạn thu nhập } \\
\text { trung bình }\end{array}$ \\
\hline Hệ số Gini & 0.49 & 0.37
\end{tabular}

Nguồn: Được tính toán từ cơ sở dữ liệu của Ngân hàng thế giới cho các nhóm nước thu nhập trung bình, http://www.worldbank.org/en/country/mic $(12 / 04 / 2019)$ [7]

\section{* Khu vục phi chính thức:}

Các nước thu nhập trung bình hiện nay cũng đang phải đối mặt với khu vực phi chính thức lớn hơn rất nhiều so với các nước công nghiệp hoá thành công ở Đông Á. Bên cạnh đó, các nước thu nhập trung bình hiện nay cũng mất rất lâu để đạt đến điểm ngoặt Lewis trong mô hình hai khu vực của Lewis [10], được đặc trưng bởi chuyển dịch lớn lao động ra khỏi khu vực nông thôn và di cư ra thành thị. Khu vực phi chính thức với phần lớn là lao động kỹ năng thấp, lương thấp và năng suất cũng thấp. Bảng 4 cung cấp sự khác biệt về khu vực phi chính thức giữa hai nhóm nước thu nhập trung bình hiện nay và các nước thành công ở Đông Á khi đang ở giai đoạn thu nhập trung bình. Khu vực phi chính thức lớn sẽ ảnh hưởng đến các thể chế liên quan đến phát triển thị trường lao động và phân bổ nguồn lực.

Bảng 4. Khu vực phi chính thức giữa hai nhóm nước

\begin{tabular}{lll}
\hline & $\begin{array}{l}\text { Các nước thu } \\
\text { nhập trung } \\
\text { bình hiện nay } \\
(2014)\end{array}$ & $\begin{array}{l}\text { Các nước } \\
\text { Đông Á ở giai } \\
\text { đoạn thu nhập } \\
\text { trung bình }\end{array}$ \\
\hline $\begin{array}{l}\text { Nền kinh tế } \\
\text { bong bóng (tỷ }\end{array}$ & \\
lệ \% của GDP \\
mà không chịu \\
thuế và quy \\
định)
\end{tabular}

Nguồn: Ngân hàng thế giới [3]. 


\section{* Đầu tu trục tiếp nước ngoài (FDI):}

FDI trở thành động lực rất quan trọng để đưa một nền kinh tế từ thu nhập thấp lên thu nhập trung bình như hình 2 đã chỉ ra. Đối với các nước công nghiệp hoá thành công ở khu vực Đông Á thì không tồn tại sự tách rời giữa doanh nghiệp trong nước và doanh nghiệp nước ngoài. Cho đến nay, Trung Quốc đã rất thành công khi tạo sự liên kết và kết nối rất tốt giữa kinh tế nội địa và khối FDI khi thay đổi thể chế yêu cầu chuyển giao hoặc liên doanh nếu muốn đầu tư vào thị trường Trung Quốc. Tuy nhiên, kết quả của liên kết dọc và ngang giữa $\mathrm{FDI}$ và nền kinh tế trong nước lại ít được nhìn thấy ở các nước thu nhập trung bình hiện nay. Khu vực FDI đóng góp rất lớn và trục chính cho nền kinh tế của các nước này. Nhiều ngành chế tạo ở các nước ASEAN như Malaysia, Thái Lan và Việt Nam bị chi phối chủ yếu bởi các tập đoàn đa quốc gia, đây là những doanh nghiệp lớn nhất như Samsung Việt Nam (Bộ Kế hoạch và Đầu tư [11]). Các doanh nghiệp FDI chiếm đến trên $50 \%$ các doanh nghiệp chế tạo lớn nhất ở Malaysia và Thái Lan. ${ }^{2}$ Điều này ngược lại với các nước công nghiệp hoá thành công ở Đông Á, khi đang ở giai đoạn thu nhập trung bình, thì các công ty trong nước chiếm phần lớn hoạt động xuất khẩu hàng chế tạo. Các công ty đa quốc gia hiếm khi đầu tư mạnh vào $R \& D$ ở các nước thu nhập trung bình. Yusuf và Nabeshima [12] nghiên cứu cho thấy, FDI đã không giúp nâng cao đáng kể năng lực nghiên cứu của Malaysia khi khu vực FDI chiếm tỷ trọng lớn trong cơ cấu chế tạo của quốc gia này.

\section{Bài học rút ra cho Việt Nam}

Việt Nam cũng như nhiều nước thu nhập trung bình khác khi không có điều kiện và bối cảnh kinh tế thuận lợi mà các nước Đông Á như Hàn Quốc, Đài Loan, và Singapore có được khi đang ở giai đoạn trung bình. Tuy nhiên, ngoài các yếu tố về sự khác biệt liên quan đến đặc điểm lịch sử, có những yếu tố chung mà các nước đang ở mức thu nhập trung bình hiện nay có thể học hỏi từ các nước đã chuyển đổi thành công, đó chính là:

- Thúc đẩy môi trường để tăng tính kết nối giữa doanh nghiệp có vốn đầu tư nước ngoài và doanh nghiệp trong nước. Sự thành công của Trung Quốc trong giai đoạn từ 1978 đến 2018 là minh chứng rõ nét trong việc thúc đẩy sự liên kêt dọc và liên kết ngang giữa FDI và nền kinh tế trong nước. Tuy nhiên, các thay đổi về thể chế gắn liền với chuyển giao công nghệ trong thực hiện Luật đầu tư nước ngoài đang chịu nhiều sức ép từ phía các nước phát triển trong việc bảo vệ bản quyền và hạn chế chuyển giao sang các nước đang phát triển. Hệ thống công nghiệp phụ trợ phát triển với đầu tư chuyên sâu và đảm bảo tính chuyển giao cũng như môi trường thể chế để hỗ trợ doanh nghiệp trong nước tiếp cận công nghệ tiền tiến, làm chủ công nghệ là rất quan trọng để từ đó khắc phục khoảng cách và sự tách biệt giữa khu vực có vốn đầu tư nước ngoài và nền kinh tế trong nước, từng bước tiến tới không phụ thuộc vào FDI và thúc đẩy tính tự cường của doanh nghiệp trong nước. Chừng nào còn phụ thuộc toàn bộ vào $\mathrm{FDI}$ cho khu vực chế tạo và xuất khẩu thì chừng đó chưa có cơ hội để thoát khỏi bẫy thu nhập trung bình.

Rõ ràng thúc đẩy quá trình liên kết trong nước từ các dự án FDI đang là thách thức mà Việt Nam phải đối mặt trong việc kiến tạo phát triển và tạo đà để chuyển từ $\mathrm{C}$ đến $\mathrm{D}$ như trong Hình 1 đã chỉ ra. Quá trình này đỏi hỏi gắn liền với độ sâu công nghiệp và sự phát triển mạnh của ngành công nghiệp hỗ trợ, qua đó tăng khả năng tích luỹ và nâng cao kiến thức từ các hoạt động sáng tạo. Đối với các nước đi sau, việc thu hút FDI nhằm tận dụng được yếu tố vốn, công nghệ, và tri thức quản lý, từ đó tiến tới làm chủ công nghệ. Như vậy, FDI phải đặt trong chiến lược tổng thể, trong đó quy định những ngành, lĩnh vực cần thu hút FDI, gắn với các ngành có giá trị gia tăng cao và hàm lượng công nghệ. Bên cạnh

\footnotetext{
${ }^{2}$ Euromoney Institutional Investor Service (EMIS): http://site.securities.com.proxy.library.emory.edu/ph $\mathrm{p} /$ companies/quick-screener/screener?subp=
} 
đó, các nước thường khuyến khích phát triển hình thức liên doanh với doanh nghiệp trong nước để thúc đẩy học hỏi chuyển giao. Ngoài ra ngành công nghiệp phụ trợ cần phát triển để hỗ trợ các dự án FDI, qua đó thúc đẩy liên kết theo chiều dọc.

- Đầu tư mạnh vào giáo dục gắn liền với nghiên cứu và phát triển $(R \& D)$. Tăng đội ngũ tham gia $R \& D$ là tiền đề rất quan trọng để tiến tới xu hướng nâng cấp công nghệ và tạo tiền đề để thoát khỏi bẫy thu nhập trung bình. Hệ thống giáo dục hướng tới đào tạo nhân lực có thể đáp ứng được yêu cầu nâng cao chất lượng $\mathrm{R} \& \mathrm{D}$, đồng thời tăng cường thúc đẩy sự hợp tác giữa các doanh nghiệp tư nhân, viện nghiên cứu, các trường đại học và đổi mới các chương trình đào tạo.

- Giảm bớt tình trạng bất bình đẳng và quy mô của khu vực phi chính thức. Tiền đề mà các nước thu nhập trung bình thành công trong quá trình chuyển đổi cho thấy, tình trạng bất bình đẳng không quá nghiệm trọng và khu vực phi chính thức không quá lớn sẽ là cơ hội để đảm bảo tập trung nguồn lực và ổn định môi trường kinh tế-xã hội. Việt Nam cần chú trọng các chương trình, chính sách nhằm hạn chế tình trạng bất bình đẳng thông qua các chính sách gắn liền với cải thiện sinh kế, nâng cao trình độ nhân lực, và môi trường khởi nghiệp, các chương trình an sinh xã hội, và phát triển vùng. Sự phát triển bao trùm và quan tâm đến nhóm yếu thể trong xã hội sẽ là tiền đề cơ bản để giảm thiểu tình trạng bất bình đẳng và tạo cơ hội cho mọi thành phần trong xã hội đóng góp vào quá trình phát triển, chứ không trở thành gánh nặng mà nhiều nước thu nhập trung bình hiện nay đang trải qua.

\section{Tài liệu tham khảo}

[1] Ngân hàng thế giới, Báo cáo phát triển thế giới 2012, Washington DC, 2012.

[2] Trần Văn Thọ, Cú sốc thời gian và kinh tế Việt Nam, Nhà xuất bản Tri thức, Hà Nội, 2015.

[3] Kenichi Ohno, Learning to industrialize: from given growth to policy-aided value creation, Routledge, London, 2013.

[4] I. Gill, H. Kharas, An East Asian Renaissance: Ideas for Economic Growth. Washington DC, 2007.

[5] M. Spence, The Next Convergence: The Future of Economic Growth in a Multispeed World. New York, NY: Farrar, Straus, and Giroux, 2011.

[6] D. Rodrik, One Economics Many Recipes: Globalization, Institutions, and Economic Growth. Princeton, NJ: Princeton University Press, 2007.

[7] The World Bank, Cơ sở dữ liệu dành cho các nước thu nhập trung bình của Ngân hàng thế giới, http://www.worldbank.org/en/country/mic, 2019 (truy cập ngày 10-12/4/2019).

[8] North, Douglass, Institutions, Institutional Change and Economic Performance. New York: Cambridge University Press, 1990.

[9] Keefer, Philip, Organizing for Prosperity: Collective Action, Political Parties and the Political Economy of Development, Policy Research Working Paper 6583. Washington DC, 2013.

[10] Lewis, W. Arthur, Economic Development with Unlimited Supplies of Labor. in A.N. Agarwala and S.P Singh eds., The Economics of Underdevelopment, Oxford, 1954.

[11] Bộ Kế hoạch và Đầu tư, Báo cáo tổng kết 30 năm huy động vốn FDI ở Việt Nam, Kỷ yếu hội thảo tổng kết 30 năm thu hút FDI, Hà Nội, 2018

[12] Yusuf, Shahid, Kaoru Nabeshima, Tiger Economies Under Threat: A Comparative Analysis of Malaysia's Industrial Prospects and Policy Options. New York: Cambridge University Press, 2009. 